\title{
Efeito de absorvedor de etileno na conservação de mamão “Golden”, armazenado à temperatura ambiente
}

\author{
Danieele Fabíola Pereira da Silva ${ }^{1}$, Luiz Carlos Chamhum Salomão², Paulo Roberto Cecon ${ }^{3}$, \\ Dalmo Lopes de Siqueira ${ }^{2}$
}

\begin{abstract}
RESUMO
O objetivo foi determinar a dose de permanganato de potássio $\left(\mathrm{KMnO}_{4}\right)$, associada à embalagem plástica, mais eficiente em retardar o amadurecimento do mamão ‘Golden', armazenado sob temperatura ambiente. Conjuntos de três frutos com massa média unitária de 278,8 $\pm 18,9 \mathrm{~g}$ foram embalados em filmes de polietileno de baixa densidade, nos quais foram incluídos sachês, contendo vermiculita impregnada com o $\mathrm{KMnO}_{4}$, nas doses de 0,0; 1,0; 2,0; 3,0 e 4,0 g/ embalagem. Os frutos embalados foram armazenados durante 15 dias, a 20,0 $\pm 0,5{ }^{\circ} \mathrm{C}$ e $90 \pm 5 \%$ de UR. Após esse período, foram mantidos na mesma temperatura, porém, fora das embalagens. As avaliações foram feitas no dia da retirada das embalagens e nos cinco dias consecutivos. Foram avaliados a concentração de $\mathrm{CO}_{2}$ no interior das embalagens, a produção de $\mathrm{CO}_{2}$, a cor da casca, a perda de massa da matéria fresca do fruto e a firmeza da polpa, o extravasamento de solutos, o teor de sólidos solúveis e a concentração de etanol da polpa. Após 15 dias de permanência nas embalagens, os frutos tratados com $\mathrm{KMnO}_{4}$ apresentaram menores produção de $\mathrm{CO}_{2}$, índice de cor da casca, perda de eletrólitos celulares e teor de etanol, porém, maior firmeza da polpa, quando comparados com frutos sem aplicação de $\mathrm{KMnO}_{4}$, indicando que os frutos não tratados tiveram amadurecimento antecipado. Após a retirada das embalagens, os frutos tratados com $\mathrm{KMnO}_{4}$ permaneceram firmes durante dois dias de avaliação. A dose de 1,0 g de $\mathrm{KMnO}_{4}$ /embalagem foi a mais indicada para as condições do experimento.
\end{abstract}

Palavras-chave: Carica papaya L., atmosfera modificada passiva, permanganato de potássio

\section{ABSTRACT}

\section{Ethylene absorber in conservation of 'Golden’ papaya stored at room temperature}

The objective of this work was to determine the most efficient potassium permanganate $\left(\mathrm{KMnO}_{4}\right)$ dose associated with plastic packaging in delaying processes related to ripening of 'Golden' papaya stored under room temperature. Groups of three fruits with unitary average weight of 278,8 $\pm 18,9$ g were wrapped in low-density polyethylene bags with $\mathrm{KMnO}_{4}$ sachets, in the doses of $0.0,1.0,2.0,3.0$ and $4.0 \mathrm{~g} / \mathrm{bag}$. The wrapped fruits were stored for 15 days at 20.0 $\pm 0.5^{\circ} \mathrm{C}$ and $90 \pm 5 \% \mathrm{RH}$. After this period, the fruits were removed from the bags and were kept in the same environment. In the beginning of the storage, in the day of the removal of the bags ( $15^{\text {th }}$ day of storage), and 1, 2, 3, 4 and 5 days after, concentration of $\mathrm{CO}_{2}$ within the bags, $\mathrm{CO}_{2}$ production, peel color and weight loss of the fruit, consistence, electrolyte leakage, soluble solids concentration and ethanol concentration of the pulp were measured. After 15 days of permanence in the bags, $\mathrm{KMnO}_{4}$-treated fruits presented smaller production of $\mathrm{CO}_{2}$, less intense peel color, smaller electrolyte leakage, higher firmness and smaller ethanol concentration when compared to treated ones, indicating that non-treated fruits had premature ripening. After removing the packaging, the firmness of $\mathrm{KMnO}_{4}$-treated fruits did not reduce for two days and these stayed firmer than non-treated ones until the fifth day of evaluation. The dose of $1.0 \mathrm{~g} \mathrm{KMnO}_{4} / \mathrm{bag}$ was the best one for the conditions of the experiment.

Key words: Carica papaya L., modified atmosphere passive, potassium permanganate

Recebido para publicação em agosto de 2009 e aprovado em dezembro de 2010

${ }^{1}$ Engenheira-Agrônoma, Doutora. Pós-Doutoranda do Departamento de Fitotecnia, Universidade Federal de Viçosa, Av. P.H. Rolfs, s/n., 36.570-000, Viçosa, Minas Gerais, Brasil. danieele@ufv.br

²Engenheiros-Agrônomos, Doutores. Departamento de Fitotecnia, Universidade Federal de Viçosa, Av. P.H. Rolfs, s/n., 36.570-000, Viçosa, Minas Gerais, Brasil. lsalomao@ufv.br, siqueira@ufv.br

${ }^{3}$ Engenheiro-Agrônomo, Doutor. Departamento de Estatística, Universidade Federal de Viçosa, Av. P.H. Rolfs, s/n., 36.570-000, Viçosa, Minas Gerais, Brasil. cecon@dpi.ufv.br 


\section{INTRODUÇÃO}

O mamão é um fruto com potencial econômico para os mercados interno e externo. Uma das limitações para a conservação pós-colheita é a sua alta perecibilidade, resultante do elevado conteúdo de água e da taxa respiratória de alta a muito alta, portanto, com elevada produção de calor e com estrutura macia facilmente danificável (Souza et al., 2009). Por ter padrão respiratório climatérico, as transformações resultantes do amadurecimento ocorrem rapidamente, após a colheita do fruto fisiologicamente maduro, desencadeadas pela produção de etileno e pelo aumento na taxa respiratória (Paull et al., 1997; Corrêa et al., 2005; Manenoi et al., 2007; Silva et al., 2009; Souza et al., 2009). Portanto, o controle do amadurecimento é fundamental para o aumento da vida útil após a colheita.

A atmosfera modificada é uma tecnologia bastante versátil e aplicável a vários tipos de frutos e hortaliças, sendo relativamente simples e de baixo custo (Fontenele et al., 2010).

O uso de atmosfera modificada passiva, ou seja, modificação da atmosfera provocada pela respiração dos próprios frutos e não pela inclusão ativa de uma atmosfera modificada, tem como princípio básico a redução da concentração de $\mathrm{O}_{2}$ e acréscimo da concentração de $\mathrm{CO}_{2}$, buscando-se a extensão da vida útil pós-colheita de frutos (Santos et al., 2005). A atmosfera modificada passiva, por meio do uso de filmes plásticos, pode retardar o processo de maturação dos frutos, por alteração da concentração inicial dos gases presentes na embalagem. A concentração de gases resultante nas embalagens depende de alguns fatores, como: taxa de permeabilidade da embalagem a gases, hermeticidade da soldagem, relação área e volume da embalagem e presença de absorvedores (Neves et al., 2004).

Sua eficácia pode ser ampliada pela associação com absorvedores de etileno, como o permanganato de potássio $\left(\mathrm{KMnO}_{4}\right)$. De acordo com Resende et al. (2001), absorvedores de etileno, como o $\mathrm{KMnO}_{4}$ absorvem e oxidam o etileno liberado pelo próprio fruto durante o amadurecimento, prolongando a fase pré-climatérica e a vida pós-colheita.

O uso de polietileno de baixa densidade (PEBD), associado ao absorvedor de etileno (sachês contendo $9 \mathrm{~g}$ de $\mathrm{KMnO}_{4}$ ), em mamão 'Sunrise Golden' , armazenado por 12 dias a $25^{\circ} \mathrm{C}$, evitou a perda de água excessiva, propiciando melhor consistência da polpa e, consequentemente, reduzindo os prejuízos na massa e na aparência (OliveiraJúnior et al., 2004).

Silva et al. (2005), estudando a emissão de etileno de mamão ‘Golden', durante armazenamento a $25^{\circ} \mathrm{C}$, por oito dias, na presença e ausência de $\mathrm{KMnO}_{4}$ (controle), obser- varam que o tratamento-controle resultou em picos climatéricos mais pronunciados, com taxas mais altas de emissão de etileno, enquanto a presença do $\mathrm{KMnO}_{4}$ atenuou a emissão de etileno. No sexto dia de armazenamento, a presença do absorvedor foi responsável pela redução de 90\% na emissão de etileno. Em média, a taxa de emissão deste foi cerca de $50 \%$ mais baixa, por causa da presença do $\mathrm{KMnO}_{4}$, em relação aos frutos-controle.

Semelhantemente, Corrêa et al. (2005) também concluíram que o $\mathrm{KMnO}_{4}$ atua diretamente, absorvendo e oxidando o etileno do ambiente e, indiretamente, reduzindo a síntese autocatalítica de etileno em mamão ‘Golden’. De acordo com Resende et al. (2001) e Chaves et al. (2007), o $\mathrm{KMnO}_{4}$, em sachês ou impregnado em embalagens plásticas, ou, ainda, em filtros químicos, absorve e oxida o etileno liberado pelo próprio fruto durante o amadurecimento, prolongando a fase pré-climatérica e a vida pós-colheita. A oxidação do etileno pelo $\mathrm{KMnO}_{4}$ leva à formação, inicialmente, de acetaldeído $\left(\mathrm{CH}_{3} \mathrm{CHO}\right)$, sendo este oxidado a ácido acético $\left(\mathrm{CH}_{3} \mathrm{COOH}\right)$ que, havendo $\mathrm{KMnO}_{4}$ suficiente, será convertido em água e gás carbônico (SORBENTSYSTEMS, 2010).

Condições experimentais utilizadas por vários autores, em estudos com cherimoia (Chaves et al. 2007), morango (Kim \& Wills, 1998), pinha (Bhadra \& Sen,1997), kiwi (Hong et al., 1996), abacate (Correa et al., 1995), maçã (Amarante \& Steffens, 2009), caqui (Neves et al., 2006) e mirtilo (Brackmann et al., 2010), variaram quanto à espessura do filme de polietileno, com ou sem perfurações, usando ou não absorvedor de etileno e variações na temperatura de armazenamento. No entanto, todos eles acreditaram que o uso de atmosfera modificada, juntamente com absorvedores de etileno e baixas temperaturas, levou a um aumento da vida útil dos frutos, aumentando a concentração de $\mathrm{CO}_{2}$, reduzindo a perda de massa fresca dos frutos e a respiração, inibindo a produção de etileno e, consequentemente, reduzindo o metabolismo do fruto.

O objetivo foi determinar a dose de $\mathrm{KMnO}_{4}$, associada à embalagem plástica mais eficiente em retardar os processos relacionados com o amadurecimento do mamão 'Golden', armazenado à temperatura ambiente.

\section{MATERIAL E MÉTODOS}

Os frutos foram obtidos de pomar comercial no Município de Linhares, Estado do Espírito Santo, Brasil. Mamões 'Golden' foram colhidos no estádio 1 de amadurecimento, ou seja, com até $15 \%$ da área superficial da casca amarela, no dia 03 de maio de 2006. Após a colheita, os frutos foram transportados para a casa de embalagem, onde foram selecionados quanto ao tamanho e estádio de amadurecimento, eliminando-se aqueles com defeitos fí- 
sicos, distúrbios fisiológicos e estádio de amadurecimento diferente de 1. Em seguida, foram lavados em água corrente e tratados com solução aquosa de cloro $1 \%$. Posteriormente, foram acondicionados em caixas de papelão e transportados em caminhonete, sem refrigeração, para o Laboratório de Análise de Frutas da Universidade Federal de Viçosa, em Viçosa, Estado de Minas Gerais, Brasil, chegando aproximadamente $36 \mathrm{~h}$ após a colheita.

No laboratório, efetuaram-se nova seleção e nova padronização, utilizando-se os frutos com massa de $278,8 \pm 18,9$ g. Em seguida, os frutos foram imersos em solução de fungicida Prochloraz (Sportak $450 \mathrm{CE}$, da empresa Hoechst Schering AgrEvo UK Ltd. - Inglaterra), na dose de 49,5 g/100 L de água, por 5 min, e secados ao ar.

Foram acondicionados três frutos por embalagem hermética de polietileno de baixa densidade $(35 \mathrm{~cm}$ altura x 25 $\mathrm{cm}$ de largura e $28 \mu \mathrm{m}$ de espessura), da qual o ar foi retirado, parcialmente, com o auxílio de um aspirador de pó. No interior de cada embalagem, foram incluídos sachês de vermiculita expandida, impregnados com $\mathrm{KMnO}_{4}$ em cinco doses ( $0 ; 1,0 ; 2,0 ; 3,0$; e $4,0 \mathrm{~g})$, sendo a dose $0 \mathrm{~g}$ referente ao tratamento controle.

Após a embalagem, os frutos foram armazenados durante 15 dias a $20,0 \pm 0,5^{\circ} \mathrm{C}$ e umidade relativa do ar de 90 $\pm 5 \%$. Após esse período, os frutos foram retirados das embalagens e mantidos nas mesmas condições de armazenamento, até o completo amadurecimento. As amostragens foram feitas no início do armazenamento (dia zero), no $15^{\circ}$ dia de armazenamento, e, a partir daí, após 1 , 2, 3, 4 e 5 dias da retirada das embalagens.

O experimento foi conduzido em parcelas subdivididas, tendo-se, nas parcelas, as cinco doses de $\mathrm{KMnO}_{4} \mathrm{e}$, nas subparcelas, os cinco dias após a retirada dos frutos das embalagens. O delineamento experimental foi inteiramente casualizado, com três repetições, e a unidade experimental composta por três frutos. Os dados foram analisados por meio das análises de variância e regressão. Independentemente da interação dose e dia ser ou não significativa, optou-se pelo seu desmembramento, dado o interesse em estudo. Também foi realizado o teste de Dunnett, a 5\% de probabilidade, para comparar a testemunha (início do armazenamento - dia zero) com as cinco doses de $\mathrm{KMnO}_{4}$.

Para as análises de concentração de $\mathrm{CO}_{2}$ no interior das embalagens foi montado um experimento adicional, com as cinco doses de $\mathrm{KMnO}_{4}$ e cinco repetições, sendo três frutos por unidade experimental. Septos de silicone foram inseridos sobre as embalagens para a retirada das amostras gasosas, com o auxílio de seringa de $1 \mathrm{~mL}$. As análises foram realizadas nos períodos de 4, 8, 12 e 24 h e, a partir daí, nos períodos de 2, 3, 4, 5, 6, 7 e 15 dias. A análise estatística utilizada para essa análise e a do teor de etanol na polpa foi descritiva.
Os frutos foram avaliados quanto à concentração de $\mathrm{CO}_{2}$ no interior das embalagens, produção de $\mathrm{CO}_{2}$ ou taxa respiratória dos frutos após a retirada das embalagens, índice de cor da casca, perda de massa da matéria fresca do fruto, perda de consistência, extravasamento de solutos, teor de sólidos solúveis e teor de etanol da polpa. A análise de concentração de $\mathrm{CO}_{2}$ no interior das embalagens foi realizada com frutos do experimento adicional.

A concentração de $\mathrm{CO}_{2}$ no interior das embalagens e a produção de $\mathrm{CO}_{2}$ foram determinadas por cromatografia gasosa, em cromatógrafo Gow Mac série 550, com detector de condutividade térmica, equipado com coluna de alumínio preenchida com porapak Q. As condições de trabalho foram: fluxo de $40 \mathrm{~mL}$ por minuto de gás hélio, que foi o gás de arraste; corrente elétrica de 150 $\mathrm{mA}$; temperaturas da coluna, do detector e do injetor de 50,70 e $80^{\circ} \mathrm{C}$, respectivamente, e temperatura ambiente de 20 a $23^{\circ} \mathrm{C}$. Os resultados foram expressos em \% ou em mg de $\mathrm{CO}_{2} \mathrm{~kg}^{-1} \cdot \mathrm{h}^{-1}$.

A evolução da coloração da casca foi determinada segundo a escala visual descrita por Martins \& Malavassi (2003), atribuindo-se a nota 1 para frutos com até 15\% da sua superfície com cor amarela, 2 para frutos com 15 a $25 \%$ da sua superfície de cor amarela, 3 para frutos com 25 a $50 \%$ da sua superfície de cor amarela, 4 para frutos com 50 a $75 \%$ da sua superfície de cor amarela e 5 para frutos com mais de $75 \%$ da sua superfície de cor amarela. A perda de massa de matéria fresca foi determinada por meio gravimétrico.

Para a perda de massa de matéria fresca, os frutos foram pesados em balança com precisão de $0,1 \mathrm{~g}$ no início do armazenamento, no dia da retirada das embalagens e, a partir daí, diariamente. Os resultados foram expressos em porcentagens, considerando-se a diferença entre o peso inicial do fruto e aquele obtido em cada período de amostragem; foi considerado o dia inicial do armazenamento como perda de massa de matéria fresca zero (0).

Para a determinação da consistência da polpa, foi retirada uma porção da casca, na região mediana dos frutos, e aplicada uma força por meio da ponteira (12 mm de diâmetro), de um penetrômetro digital SHIMPO modelo DFS 100 (Digital Force Gauge). Os resultados foram dados pela média da força aplicada aos três frutos da parcela, sendo uma penetração por fruto, e expressos em $\mathrm{kPa}$.

As mudanças que ocorrem na funcionalidade das membranas são o resultado do decréscimo da fluidez dos lipídeos, das modificações estruturais e do declínio das proteínas da membrana durante a senescência. Essas alterações nas membranas podem ser medidas pela análise de extravasamento de solutos. A análise do extravasamento de solutos da polpa foi feita de acordo com metodologia descrita por Serek et al. (1995). O 
teor de SS foi determinado com o auxílio de um refratômetro manual Atago modelo N1, com leitura na faixa de 0 a $32^{\circ}$ Brix.

$\mathrm{O}$ teor de etanol foi determinado por cromatografia a gás, utilizando-se cromatógrafo a gás CG modelo 37-D, com detector de ionização de chama equipado com uma coluna de aço inoxidável, empacotada com porapak Q. O gás de arraste foi o $\mathrm{N}_{2}$, com fluxo de $30 \mathrm{~mL} /$ minuto. As temperaturas da coluna, do detector e do injetor, foram de 132, 132 e $134^{\circ} \mathrm{C}$, respectivamente. Amostras da polpa da região mediana dos frutos foram maceradas e centrifugadas a 3.300 g por $20 \mathrm{~min}$, recolhendo-se o sobrenadante. Volumes de $2 \mu \mathrm{L}$ dessa solução foram injetados em cromatógrafo, sendo o teor de etanol expresso em $\mu \mathrm{L} / \mathrm{g}$ de matéria fresca.

\section{RESULTADOS E DISCUSSÃO}

A concentração de $\mathrm{CO}_{2}$ no interior das embalagens (Figura 1) foi maior, a partir da oitava hora de armazenamento até o $2^{\circ}$ dia, para frutos com $\mathrm{KMnO}_{4}$, e até o $3^{\circ}$ dia para os não tratados. Nos frutos sem $\mathrm{KMnO}_{4}$, a concentração estabilizou-se, entre o $3^{\circ}$ e $15^{\circ}$ dia, em torno de $17 \%$ de $\mathrm{CO}_{2}$, enquanto, nos tratados, houve decréscimo do $2^{\circ}$ ao $6^{\circ}$ dia e estabilizou-se entre o $6^{\circ}$ e o $15^{\circ}$ dia de armazenamento, com concentração entre 8 e $10 \%$ de $\mathrm{CO}_{2}$. Em geral, maiores doses de $\mathrm{KMnO}_{4}$ resultaram em menores concentrações de $\mathrm{CO}_{2}$ no interior das embalagens.

Resultados semelhantes foram encontrados por Oliveira-Júnior et al. (2004). Estes autores observaram que a concentração de $\mathrm{CO}_{2}$ em mamões ‘Golden’ em embalagem de polietileno ( $30 \mu \mathrm{m}$ ) com sachê, contendo $2,5 \mathrm{~g} \mathrm{KMnO}_{4}$ ' $\mathrm{kg}$ fruto, manteve-se em torno de $9,7 \%$ no $2^{\circ}$ dia de armazenamento, com tendência decrescente após o $2^{\circ}$ dia de armazenamento. De acordo com esses autores, isso se deve à redução da concentração do etileno autocatalítico no interior das embalagens, o qual acelera o metabolismo do fruto e, consequentemente, o seu amadurecimento. Amarante \& Steffens (2009), trabalhando com sachê de $\mathrm{KMnO}_{4}(10 \mathrm{~g})$ em maçã 'Royal Gala', observaram redução na concentração de $\mathrm{CO}_{2}$, com o emprego de um ou dois sachês do produto no interior das embalagens, o que ocasionou maior retenção de cor verde na casca e de firmeza de polpa e menor incremento no teor de SS ( ${ }^{\circ}$ Brix) nos frutos, especialmente após uma semana de comercialização simulada em condições ambientes.

Apesar de altas concentrações de $\mathrm{CO}_{2}$ no interior das embalagens reduzirem a taxa de produção de etileno e tornarem os frutos menos sensíveis à sua ação (Brackmann et al., 2006), concentrações prejudiciais de etileno podem acumular-se, em condições de atmosfera modificada, para frutos sem $\mathrm{KMnO}_{4}$ (tratamento controle), o que pode explicar a alta concentração de $\mathrm{CO}_{2}$ no interior das embalagens para frutos do tratamento controle do presente trabalho. Para os tratamentos com $\mathrm{KMnO}_{4}$, as baixas concentrações de $\mathrm{CO}_{2}$ podem ser explicadas em consequência do uso desse absorvedor de etileno.

A produção de $\mathrm{CO}_{2}$ (Tabela 1) apresentou diferença, a $5 \%$ de probabilidade, pelo teste de Dunnett, entre a testemunha (início do armazenamento) e o tratamento sem $\mathrm{KMnO}_{4}$, no dia da retirada dos frutos das embalagens, enquanto, nos demais tratamentos não houve diferença, indicando que os frutos tratados com $\mathrm{KMnO}_{4}$ permaneceram na fase pré-climatérica, após 15 dias de armazenamento. Após a retirada dos frutos das embalagens, aqueles do tratamento sem $\mathrm{KMnO}_{4}$ apresentaram maior produção de $\mathrm{CO}_{2}$ em relação aos com $\mathrm{KMnO}_{4}$ (Figura 2).

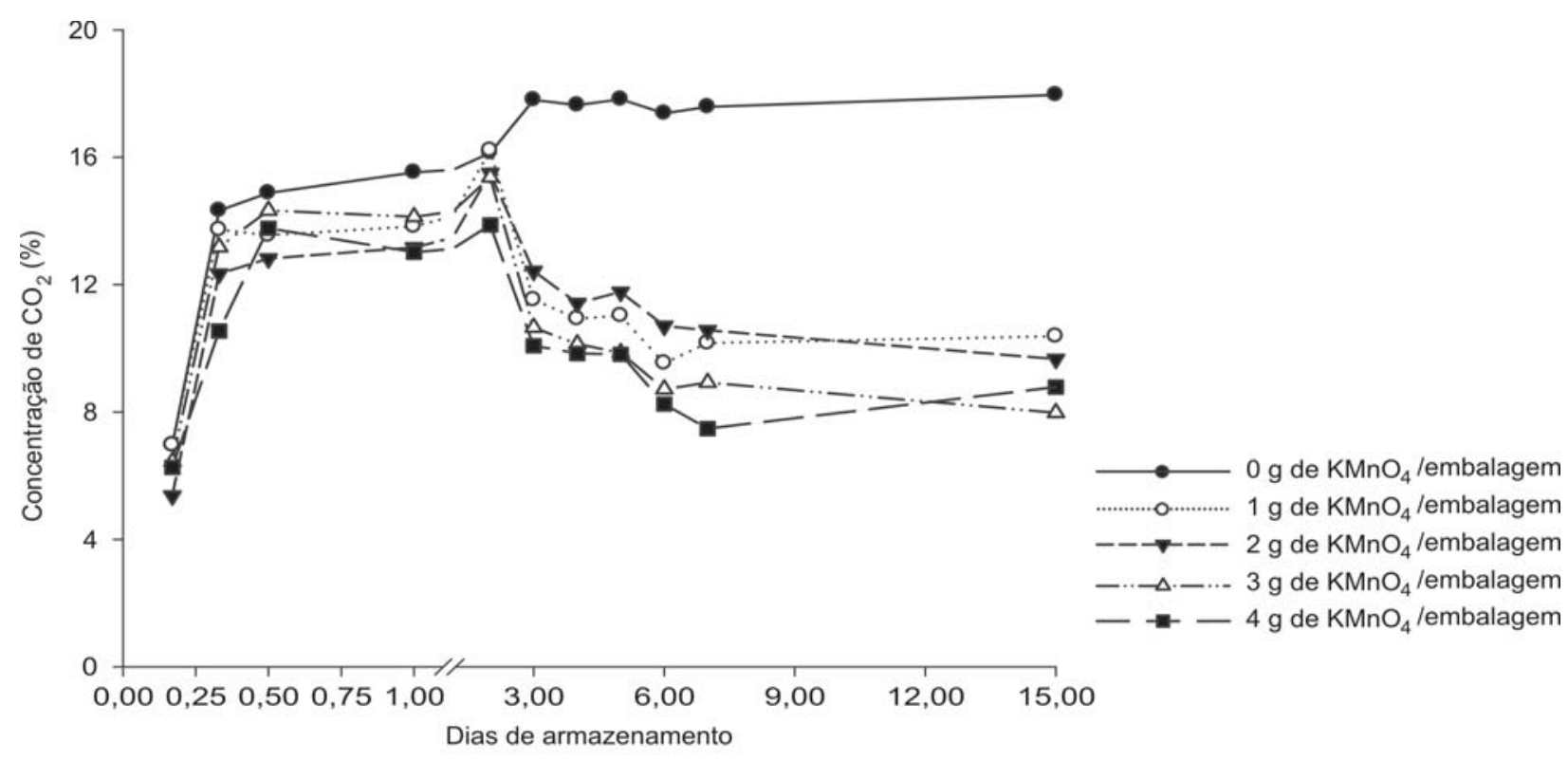

Figura 1. Concentração de $\mathrm{CO}_{2}$ no interior das embalagens com mamão ‘Golden’, durante 15 dias de armazenamento a 20,0 $\pm 0,5^{\circ} \mathrm{C}$. 
Os frutos sem $\mathrm{KMnO}_{4}$ atingiram o pico climatérico respiratório entre $1^{\circ}$ e o $2^{\circ}$ dia após a retirada das embalagens, enquanto os frutos tratados com $\mathrm{KMnO}_{4}$ só chegaram ao pico climatérico no $3^{\circ}$ dia após a retirada das embalagens. Além disso, a taxa respiratória dos frutos sem $\mathrm{KMnO}_{4}$ foi de $170 \mathrm{mg} \mathrm{CO} \mathrm{kg}^{-1} \cdot \mathrm{h}^{-1}$ no pico climatérico, enquanto, nos frutos com esse composto, ela variou de 130 a $150 \mathrm{mg} \mathrm{CO}_{2} / \mathrm{kg} / \mathrm{h}$, evidenciando-se o efeito do $\mathrm{KMnO}_{4}$ sobre o metabolismo dos frutos.

O índice de cor da casca apresentou diferença a 5\% de probabilidade, pelo teste de Dunnett, apenas entre a testemunha (início do armazenamento) e o tratamento sem $\mathrm{KMnO}_{4}$ no dia da retirada dos frutos das embalagens, indicando que nos frutos tratados com $\mathrm{KMnO}_{4}$ a cor da casca permaneceu inalterada, após os 15 dias de armazenamento (Tabela 1). Esse resultado confirma os de Oliveira-Júnior et al. (2004), que, trabalhando com mamão ‘Golden', obtiveram frutos completamente verdes por 12 dias.
Em frutos não tratados com $\mathrm{KMnO}_{4}$ (Figura 3), observou-se que, no dia da retirada da embalagem, eles já apresentavam índice de cor da casca, em média, 3,09, enquanto os frutos tratados com $\mathrm{KMnO}_{4}$ ainda estavam com índice de cor da casca 1,9, em média. Isso evidencia o efeito do $\mathrm{KMnO}_{4}$ em manter a coloração verde dos frutos mesmo após a retirada das embalagens e da remoção dos sachês.

Verificou-se que o $\mathrm{KMnO}_{4}$ foi eficiente em retardar o desenvolvimento do índice de cor da casca, em comparação com os frutos não tratados (Figura 3). Isso porque frutos sem $\mathrm{KMnO}_{4}$, no $3^{\circ}$ dia de avaliação, apresentavamse com índice de cor da casca 3,6, enquanto, em frutos tratados no mesmo período, o índice de cor da casca era de 4,5 .

Esses resultados estão de acordo com Cenci et al. (1999), que, trabalhando com mamão 'Sunrise' embalado em filme de polietileno mais sachês de $\mathrm{KMnO}_{4}$ (2 sachês, com 10 g cada, em caixa contendo 12 frutos), armazenado

Tabela 1. Médias da produção de $\mathrm{CO}_{2}\left(\mathrm{mg} \mathrm{CO} \mathrm{kg}^{-1} \cdot \mathrm{h}^{-1}\right)$, índice de cor da casca (IC), perda de matéria fresca (PMF), consistência da polpa (CP), extravasamento de solutos (perda de eletrólitos - ES) e teor de sólidos solúveis (SS) de mamão 'Golden' tratado com diferentes doses de $\mathrm{KMnO}_{4}$, após 15 dias de armazenamento

\begin{tabular}{|c|c|c|c|c|c|c|}
\hline Tratamentos & Prod. $\mathrm{CO}_{2}$ & IC & PMF (\%) & $\mathrm{CP}(\mathrm{kPa})$ & ES (\%) & SS $\left({ }^{\circ}\right.$ Brix) \\
\hline Testemunha $^{1}$ & 92,78 & 1,7 & 0,000 & 2378,38 & 8,549 & 9,7 \\
\hline 0,0 g KMnO $4 /$ embalagem & $111,16^{*}$ & $2,7 *$ & $0,3529 *$ & $537,49 *$ & $23,855^{*}$ & $12,4^{*}$ \\
\hline $1,0 \mathrm{~g} \mathrm{KMnO}_{4} /$ embalagem & 94,96 & 2,0 & 0,2729 & 2177,08 & 15,714 & $11,8^{*}$ \\
\hline 2,0 g KMnO 4 /embalagem & 96,94 & 1,8 & $0,3981 *$ & 2356,97 & 14,998 & $11,7^{*}$ \\
\hline 3,0 g KMnO $4 /$ embalagem & 94,50 & 1,9 & $0,4779 *$ & 2220,80 & 13,829 & $11,5^{*}$ \\
\hline 4,0 g KMnO 4 /embalagem & 92,02 & 1,7 & $0,5589 *$ & 2360,61 & 11,566 & $11,3^{*}$ \\
\hline
\end{tabular}

Médias seguidas de * diferem e ns não diferem estatisticamente da testemunha (início do armazenamento), pelo teste de Dunnett a 5\% de probabilidade.

${ }^{1}$ Médias apresentadas pelos frutos no início do armazenamento, a $20,05 \pm 0,50{ }^{\circ} \mathrm{C}$.



Figura 2. Produção de $\mathrm{CO}_{2}\left(\mathrm{mg}\right.$ de $\mathrm{CO}_{2} \cdot \mathrm{kg}^{-1} \cdot \mathrm{h}^{-1}$ ) de mamões ‘Golden’ tratados com diferentes doses de $\mathrm{KMnO}_{4}$, mantidos a 20,0 \pm $0,5^{\circ} \mathrm{C}$, nos cinco dias após a retirada dos frutos das embalagens.

Rev. Ceres, Viçosa, v. 57, n.6, p. 706-715, nov/dez, 2010 
por 14 dias a $10^{\circ} \mathrm{C}$, mais três dias a $20^{\circ} \mathrm{C}$, observaram redução no desenvolvimento da cor amarela em comparação com os não tratados.

A variável perda de massa de matéria fresca apresentou diferença, a $5 \%$ de probabilidade, pelo teste de Dunnett, entre a testemunha (início do armazenamento) e os tratamentos 0,0; 2,0; 3,0; e 4,0 g de $\mathrm{KMnO}_{4}$ /embalagem, no dia da retirada dos frutos das embalagens (Tabela 1), sendo considerado o dia do armazenamento como perda de massa de matéria fresca zero (0). Apesar da diferença significativa, a perda de massa de matéria fresca foi, em geral, menor que $0,5 \%$ após 15 dias de armazenamento em embalagem plástica, o que não é suficiente para depreciar visualmente os frutos.

Observou-se que a perda de massa de matéria fresca no tratamento sem $\mathrm{KMnO}_{4}$ foi superior à dos tratamentos com $\mathrm{KMnO}_{4}$ (Figura 4). Enquanto, nos frutos sem $\mathrm{KMnO}_{4}$, no $5^{\circ}$ dia após a retirada da embalagem a perda de matéria fresca foi em torno de 5,5\%, nos frutos tratados com $\mathrm{KMnO}_{4}$, a perda média foi de apenas 3,7\% de matéria fresca.

Frutos com $\mathrm{KMnO}_{4}$ apresentaram, no final do período de armazenamento, melhor aspecto externo em relação aos frutos não tratados. De acordo com Cenci et al. (1999) perdas de massa superiores a $5 \%$ para mamão exposto em gôndolas de supermercados já são suficientes para a depreciação. Esses autores ressaltaram que, muitas vezes, essa perda é negligenciada na cadeia de comercialização.

De acordo com relatos de Finger \& Vieira (1997), a perda de água reduz o período pré-climatérico de banana e maçã, antecipando o climatérico respiratório e a produção de etileno, que caracterizam a ascensão climatérica e o amadurecimento.
Para a variável consistência da polpa, no dia da retirada dos frutos das embalagens, o tratamento sem $\mathrm{KMnO}_{4}$ diferiu a $5 \%$ de probabilidade, pelo teste de Dunnett, daqueles da testemunha (dia 15 - retirada dos frutos da embalagem), enquanto os demais tratamentos não apresentaram diferença em relação à testemunha (Tabela 1). Esses resultados indicaram que o $\mathrm{KMnO}_{4}$ foi efetivo em manter os frutos firmes durante os 15 dias de armazenamento, à semelhança dos resultados obtidos por Silva et al. (2009). Esses autores armazenaram mamão ‘Golden’ em filme de PEBD com 28 ìm de espessura, associado com sachês de $\mathrm{KMnO}_{4}$ nas doses de 0,0, 0,5, 1,0 1,5, e 2,0 g por embalagem, a 10,4 $\pm 0,9^{\circ} \mathrm{C}$ e $90 \pm$ $5 \%$ de umidade relativa, por 25 dias. Após esse período, os frutos foram retirados das embalagens e armazenados a $21 \pm 0,8$ ${ }^{\circ} \mathrm{C} \mathrm{e} 90 \pm 5 \%$ de UR até o completo amadurecimento. A consistência da polpa manteve-se elevada até o $2^{\circ}$ dia, depois caiu rapidamente, até $05^{\circ}$ dia. Observaram, também, que os frutos tratados com 0,0 g de $\mathrm{KMnO}_{4} /$ embalagem apresentaram polpa mais amolecida no $1^{\circ}$ dia após a abertura das embalagens, com posterior queda na consistência.

Os frutos dos tratamentos sem $\mathrm{KMnO}_{4}$ apresentaram consistência próxima a $540 \mathrm{kPa}$ no dia da retirada dos frutos das embalagens, a qual se reduziu para $156 \mathrm{kPa}$ no $5^{\circ}$ dia de avaliação (Figura 5). O amolecimento dos frutos ainda nas embalagens pode ter ocorrido por causa das elevadas concentrações de $\mathrm{CO}_{2}$ (Figura 1).

Os frutos tratados com $\mathrm{KMnO}_{4}$ tiveram comportamento semelhante entre si, mantendo-se firmes até o $2^{\circ}$ dia e amaciando, rapidamente, até o $4^{\circ}$ dia, num processo que coincidiu com a ascensão e pico climatéricos (Figura 2). Esses frutos mantiveram-se mais firmes em relação aos frutos sem $\mathrm{KMnO}_{4}$, em razão, provavelmente, do efeito

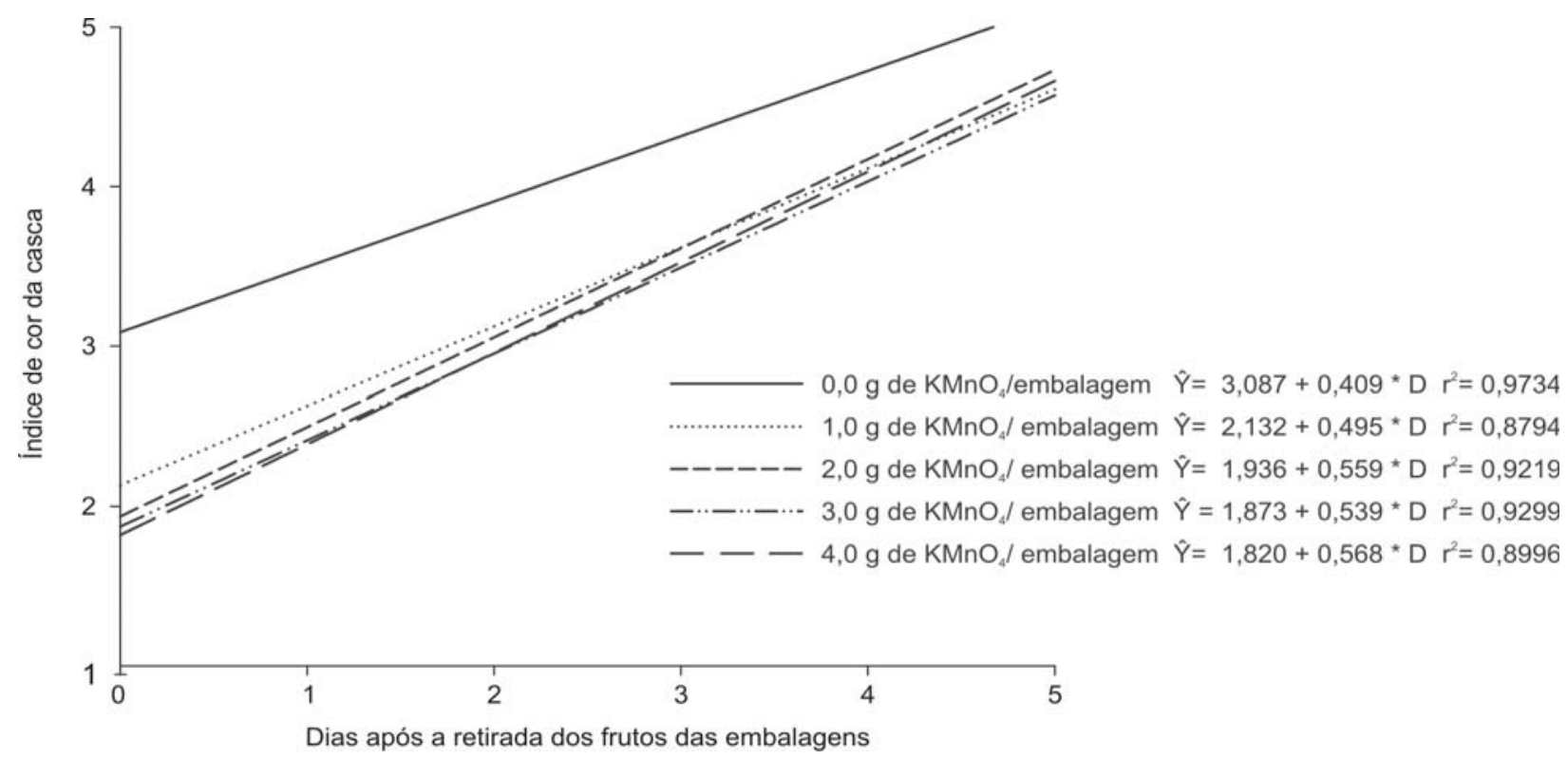

Figura 3. Estimativa do índice de cor da casca de mamões ‘Golden’ tratados com diferentes doses de $\mathrm{KMnO}_{4,}$ mantidos a 20,0 $\pm 0,5$ ${ }^{\circ} \mathrm{C}$, nos cinco dias após a retirada dos frutos das embalagens. 
sinergístico entre a embalagem e o absorvedor de etileno, o que reduziu a atividade das enzimas que hidrolisam a parede celular. No $3^{\circ}$ dia de avaliação, frutos sem $\mathrm{KMnO}_{4}$ apresentavam consistência de 187,61 kPa, enquanto frutos tratados com $\mathrm{KMnO}_{4}$ apresentaram 1.253,69 kPa. Apenas no $5^{\circ}$ dia, a consistência dos frutos com $\mathrm{KMnO}_{4}$ atingiu os valores observados nos não tratados, no dia da remoção das embalagens.

Para o tratamento sem $\mathrm{KMnO}_{4}$, no dia da retirada da embalagem, foram descartados $47 \%$ dos frutos, pois estes estavam total ou parcialmente deteriorados (podridão-mole) e com mau cheiro. Isso pode ser explicado pelo fato de esse tratamento ter apresentado valores médios de $17 \%$ de $\mathrm{CO}_{2}$ no interior das embalagens (Figura 1), o que pode ter causado fermentação. Para os frutos tratados com $\mathrm{KMnO}_{4}$ foram descartados 3,7, 7,4, 1,9 e 7,4\% das doses de 1,0; 2,0; 3,0; e 4,0 g/embalagem, respectivamente, evidenciando-se a efetividade do sistema de remoção do etileno, que reduziu significativamente a taxa de amaciamento dos tecidos, bem como retardou a deterioração.

O amaciamento da polpa é um dos principais atributos da qualidade pós-colheita do mamão, uma vez que determina se o fruto está no ponto ótimo para consumo. Na maioria das vezes, o consumidor compra o mamão após manuseio,

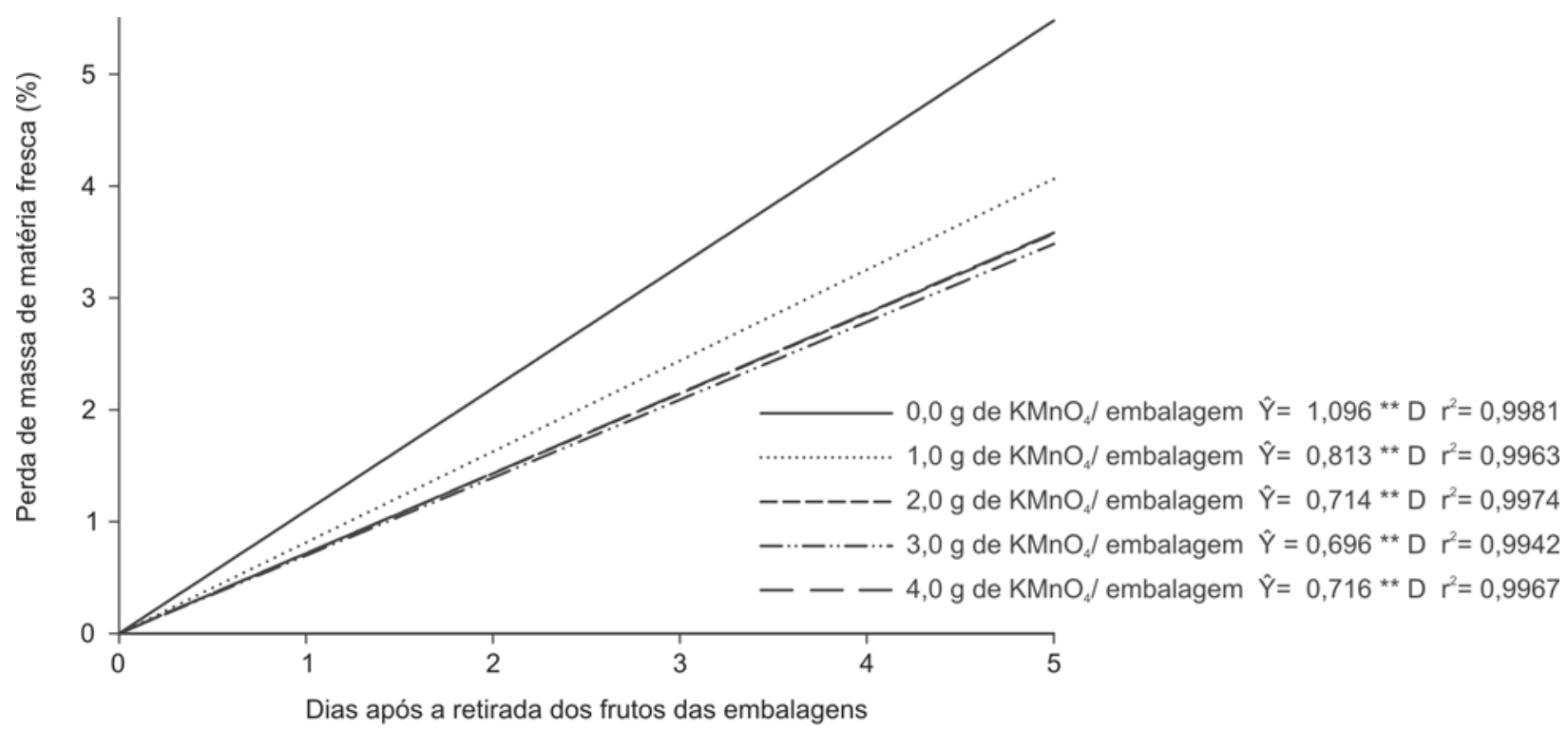

Figura 4. Estimativa da perda de matéria fresca de mamões ‘Golden’ tratados com diferentes doses de $\mathrm{KMnO}_{4}$, mantidos a 20,0 \pm 0,5 ${ }^{\circ} \mathrm{C}$, nos cinco dias após a retirada dos frutos das embalagens.



Figura 5. Estimativa da consistência da polpa mamões ‘Golden’ tratados com diferentes doses de $\mathrm{KMnO}_{4}$, mantidos a $20,0 \pm 0,5^{\circ} \mathrm{C}$, nos cinco dias após a retirada dos frutos das embalagens.

Rev. Ceres, Viçosa, v. 57, n.6, p. 706-715, nov/dez, 2010 
escolhendo os frutos mais firmes. Dessa forma, o efeito do $\mathrm{KMnO}_{4}$, após a retirada dos frutos das embalagens, tornase um importante fator, pois os frutos ficarão disponíveis por mais tempo nas gôndolas dos supermercados.

Frutos tratados com $\mathrm{KMnO}_{4}$ mantiveram a permeabilidade seletiva das membranas celulares semelhantes à dos frutos-testemunha (início do armazenamento) após 15 dias de armazenamento, a 5\% de probabilidade, pelo teste de Dunnett (Tabela 1). Isso indica que, na temperatura de armazenamento, a atmosfera modificada pelo PEBD, juntamente com o $\mathrm{KMnO}_{4}$, foi suficiente para retardar o amadurecimento por 15 dias.

A perda de eletrólitos nos frutos armazenados sem $\mathrm{KMnO}_{4}$ aumentou durante o armazenamento, quando comparada com frutos tratados com $\mathrm{KMnO}_{4}$ (Figura 6). Podese observar que, para frutos tratados com $\mathrm{KMnO}_{4}$, no $5^{\circ}$ dia após a retirada da embalagem, o extravasamento de vazamento de eletrólitos celulares ficou em torno de 33\%, enquanto, nos frutos não tratados com $\mathrm{KMnO}_{4}$, o vazamento de eletrólitos celulares no mesmo período foi de $48 \%$ (Figura 6). Altos valores de vazamento de eletrólitos celulares para frutos sem $\mathrm{KMnO}_{4}$ podem ser devidos ao fato de terem entrado na fase pós-climatérica a partir do $2^{\circ}$ dia após a retirada das embalagens e, portanto, as membranas celulares já haviam perdido sua permeabilidade seletiva.

A aceleração da perda de eletrólitos pelos frutos tratados com $\mathrm{KMnO}_{4}$ coincidiu com a fase pós- climatérica, com a perda acentuada de firmeza e com a acentuação da cor amarela da casca. Esses resultados confirmaram os de Rocha et al. (2009), que, trabalhando com banana 'Prata' com diferentes doses de $\mathrm{KMnO}_{4}$ associadas a filme de polietileno de baixa densidade, observaram que frutos tratados com $\mathrm{KMnO}_{4}$ tiveram menor vazamento de eletrólitos celulares em relação aos frutos sem $\mathrm{KMnO}_{4}$.

A variável teor de sólidos solúveis apresentou diferença a 5\% de probabilidade entre a testemunha (início do armazenamento) e os demais tratamentos, no dia da retirada dos frutos das embalagens (D) (Tabela 1).

Frutos sem $\mathrm{KMnO}_{4}$, no $5^{\circ}$ dia de avaliação, apresentavam, em média, $13,5^{\circ}$ Brix, enquanto frutos tratados no mesmo período apresentavam em média $12,5^{\circ}$ Brix. Durante todo o período após a retirada da embalagem, os frutos tratados com $\mathrm{KMnO}_{4}$ permaneceram com teor de sólidos solúveis cerca de um ponto abaixo dos não tratados, mostrando o efeito do $\mathrm{KMnO} 4$ em retardar o amadurecimento dos frutos (Figura 7).

De acordo com relatos de Chitarra \& Chitarra (2005), a emissão de voláteis pode ser utilizada como sinais de estresse dos tecidos pelo frio ou pelo calor. O aumento da concentração de compostos voláteis, como acetaldeído, etanol, acetato de etila e hexanol, é um indicativo de fermentação do produto durante o armazenamento. Dessa forma, de acordo com a Tabela 2, pode-se observar que


Figura 6. Estimativa do extravasamento de solutos da polpa de mamões 'Golden' tratados com diferentes doses de $\mathrm{KMnO}_{4}$, mantidos a $20,0 \pm 0,5^{\circ} \mathrm{C}$, nos cinco dias após a retirada dos frutos das embalagens. 
frutos sem $\mathrm{KMnO}_{4}$, tanto aos 15 dias, quanto aos 20, tiveram maiores concentrações de etanol em relação aos frutos tratados com $\mathrm{KMnO}_{4}$.

Embora o teor de etanol tenha-se reduzido de 0,2474 $\mu \mathrm{L} / g$ para $0,1456 \mu \mathrm{L} / g$, indicando degradação parcial, isso não foi suficiente para impedir danos nos frutos não tratados com $\mathrm{KMnO}_{4}$. Portanto, tanto no $15^{\circ}$ dia de avaliação, quanto no $20^{\circ}$, os valores do teor de etanol para frutos tratados com $\mathrm{KMnO}_{4}$ ficaram bem próximos aos do dia 0 , indicando que para esses frutos não ocorreu respiração anaeróbica.

A maior concentração de $\mathrm{CO}_{2}$ (Figura 1) em frutos sem $\mathrm{KMnO}_{4}$ pode ter causado anaerobiose, uma vez que apresentaram aroma mais desagradável em relação ao dos frutos tratados com $\mathrm{KMnO}_{4}$. Bender \& Brecht (2000) avaliaram a respiração e produção de etanol e etileno em mangas 'Kent' e 'Tommy Atkins', armazenadas sob reduzidas concentrações de $\mathrm{O}_{2}$ e elevadas concentrações de $\mathrm{CO}_{2}$. Observaram que elevadas concentrações de $\mathrm{CO}_{2}$ incre- mentaram a atividade respiratória e o metabolismo anaeróbico, que podem causar prejuízos à qualidade dos frutos. Concomitantemente ao aumento do metabolismo anaeróbico, em atmosferas com elevado $\mathrm{CO}_{2}$, observaram a redução da produção de etileno, e, após transferência para ar, não ocorre retomada da biossíntese de etileno nos níveis observados em mangas apenas armazenadas em ar. Segundo Burdon et al. (1996), o acúmulo de etanol pode estimular biossíntese de etileno, desencadeando a maturação e posteriores danos aos frutos.

\section{CONCLUSÕES}

O permanganato de potássio foi eficiente em manter os frutos verdes durante 15 dias de armazenamento a $20^{\circ} \mathrm{C}$.

As doses de 1 a $4 \mathrm{~g}$ de $\mathrm{KMnO}_{4}$ mantiveram as características de qualidade dos frutos após a remoção da embalagem.

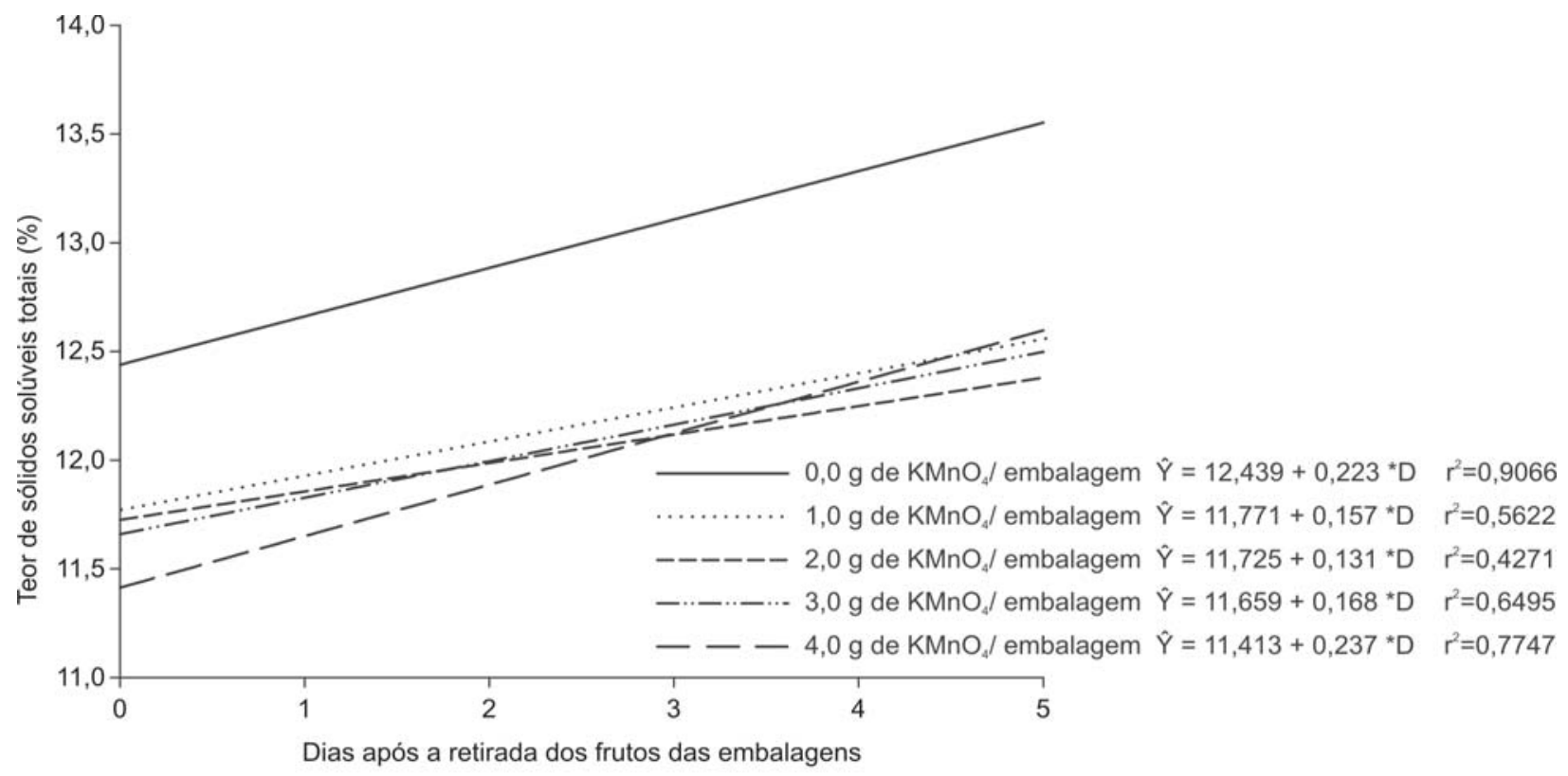

Figura 7. Estimativa do teor de sólidos solúveis totais de mamões 'Golden' tratados com diferentes doses de $\mathrm{KMnO}_{4}$ mantidos a $20,0 \pm 0,5^{\circ} \mathrm{C}$, nos cinco dias após a retirada dos frutos das embalagens.

Tabela 2. Médias do teor de etanol ( $\mu \mathrm{L} / \mathrm{g}$ de matéria fresca) da polpa de mamão ‘Golden’ tratado com diferentes doses de $\mathrm{KMnO}_{4} \mathrm{e}$ armazenado a $20,0 \pm 0,5^{\circ} \mathrm{C}$

\begin{tabular}{lccc}
\hline & \multicolumn{3}{c}{ Teor de etanol $(\mu \mathrm{L} / \mathbf{g ~ M F})$} \\
\cline { 2 - 4 } Tratamentos & \multicolumn{3}{c}{ Dias de armazenamento $^{\mathbf{1}}$} \\
\cline { 2 - 4 } & $\mathbf{0 ~ d i a s}$ & $\mathbf{1 5}$ dias & $\mathbf{2 0}$ dias \\
\hline 0,0 $\mathrm{g} \mathrm{KMnO}_{4}$ /embalagem & 0,1063 & 0,2474 & 0,1456 \\
1,0 $\mathrm{g} \mathrm{KMnO}_{4}$ /embalagem & 0,1063 & 0,0918 & 0,0869 \\
2,0 $\mathrm{g} \mathrm{KMnO}_{4}$ /embalagem & 0,1063 & 0,1161 & 0,0755 \\
3,0 $\mathrm{g} \mathrm{KMnO}_{4}$ /embalagem & 0,1063 & 0,1588 & 0,1056 \\
4,0 $\mathrm{g} \mathrm{KMnO}_{4}$ /embalagem & 0,1063 & 0,1442 & 0,0822 \\
\hline
\end{tabular}

${ }^{1}$ Os dias 0, 15 e 20 referem-se ao início do armazenamento, ao dia da retirada das embalagens (dia zero) e ao $5^{\circ}$ dia após a retirada das embalagens, respectivamente.

Rev. Ceres, Viçosa, v. 57, n.6, p. 706-715, nov/dez, 2010 


\section{AGRADECIMENTOS}

Ao Conselho Nacional de Desenvolvimento Científico e Tecnológico (CNPq), pela concessão da bolsa de mestrado e doutorado à primeira autora e da bolsa de Produtividade em Pesquisa aos demais autores.

\section{REFERÊNCIAS}

Amarante CVT \& Steffens CA (2009) Sachês absorvedores de etileno na pós-colheita de maçãs 'Royal Gala'. Revista Brasileira Fruticultura, 31:71-77.

Bender RJ \& Brecht J (2000) Respiração e produção de etanol e de etileno em mangas armazenadas sob diferentes concentrações de dióxido de carbono e oxigênio. Pesquisa Agropecuária Brasileira, 35:865-871.

Bhadra S \& Sen SK (1997) Post-harvest storage of custard apple (Annona squamosa L.) fruit var. Local Green under various chemical and wrapping treatments. Journal of Inter Academicia, $1: 322-328$.

Brackmann A, Giehl RFH, Freitas ST, Eisermann AC \& Mello AM (2006) Uso de filmes de polietileno e absorção de etileno para o transporte refrigerado de maçã 'Gala'. Semina, 27:423-428.

Brackmann A, Weber A, Giehl RFH, Eisermann AC, Sautter CK, Gonçalves ED \& Antunes LEC (2010) Armazenamento de mirtilo 'Bluegem' em atmosfera controlada e refrigerada com absorção e inibição do etileno. Revista Ceres, 57:6-11.

Burdon J, Dori S, Marinansky R \& Pesis E (1996) Acetaldehyde inhibition of ethylene in mango fruit. Postharvest Biology and Technology, 8:153-161.

Cenci AS, Soares AG, Souza ML \& Moura ML (1999) Efecto de la aplication de absorvedor de etileno $\mathrm{KMnO}_{4}$ en las características de calidade y conservación de la papaya cv. 'Sunrise Solo'. Revista Iberoamericana de Tecnologia Postcosecha, 1:150-155.

Chaves MA, Bonomo RCF, Silva AAL, Santos LS, Carvalho BMA, Souza TS, Gomes GMS \& Soares RD (2007) Uso de permanganato de potasio en la preservación post-cosecha de frutas de chirimoya. Ciencia e Tecnologia de Alimentos, 5:346-351.

Chitarra MIF \& Chitarra AB (2005) Pós-colheita de frutos e hortaliças: fisiologia e manuseio. $2^{\text {a }}$ ed. Rev. e Ampl. Lavras, UFLA. 785p.

Correa PC, Plaza Peraz JL de La \& Ruiz Altisent M (1995) No destructive tests to evaluate postharvest maturity in avocado. Agro Ciência, 11:197-200.

Corrêa SF, Filho MB, Da Silva MG, Oliveira JG, Aroucha EMM, Silva RF, Pereira MG \& Vargas H (2005) Effect of the potassium permanganate during papaya fruit ripen-ing: Ethylene production. Journal of Physique IV, 25:869-871.

Finger FL \& Vieira G (1997) Controle da perda pós-colheita de água em produtos hortícolas. Viçosa, Editora UFV. 29p. (Cadernos Didáticos, 19)

Fontenele MA, Figueiredo RW, Maia GA, Alves RE, Sousa PHMA \& Souza VAB (2010) Conservação pós-colheita de bacuri (Platonia insignis Mart.) sob refrigeração e embalado em PVC. Revista Ceres, 57:292-296.

Hong YP, Hong SS, Kim YB \& Kim SB (1996) Effect ethylene absorbent (Frubel) on quality of Hayward kiwifruit during cold storage. Journal of Agricultural Science, 38:922-926.

Kim GH \& Wills RBH (1998) Interaction of enhanced carbon dioxide and reduced ethylene on the storage life of strawberries. Journal of Horticultural Science and Biotechnology, 73:181-184.
Manenoi A, Bayogan ERV, Thumdee S \& Paull RE (2007). Utility of 1-methylcyclopropene as a papaya postharvest treatment. Postharvest Biology and Technology, 44:55-62.

Martins D dos S. \& Malavassi A (2003) Produção de mamão no Espírito Santo, como garantia de segurança quarentenária contra moscas-das-frutas. In: Zambolim L (Ed.) Manejo integrado, produção integrada, fruteiras tropicais doenças e pragas. Viçosa, UFV. p.7-36.

Neves LC, Bender RJ, Rombaldi CV \& Vieites RL (2004) Armazenagem em atmosfera modificada passiva de carambola azeda (Averrhoa carambola L.) cv. 'Golden Star'. Revista Brasileira de Fruticultura, 26:8-12.

Neves LC, Benedette RM, Silva VX, Luchetta L, Zanuzzo MR \& Rombaldi CV (2006) Comportamento pós-colheita de caquis cv. Fuyu, através da atmosfera modificada passiva e da adsorção de etileno, armazenados sob refrigeração. Revista Brasileira de Fruticultura, 28:374-379.

Oliveira-Júnior LFG, Coelho ME, Berbet PA \& Coelho FC (2004) Armazenamento de mamão 'Golden', em condições de atmosfera modificada. Revista Brasileira de Armazenamento, 29: 137-142.

Paull RE, Nishijima W, Reyes M \& Ca-valetto C (1997) Postharvest handling and losses during marketing of papaya (Carica papaya L.). Postharvest Biology and Technology, 11:165-179.

Resende JM, Boas EV de BV \& Chitarra MIF (2001) Uso de atmosfera modificada na conservação pós-colheita do maracujá amarelo. Ciência Agrotécnica, 25:159-168.

Rocha A, Salomão LCC, Bruckner CH \& Cecon PR (2009) Uso do permanganato de potássio em pós-colheita de banana 'Prata' armazenada sob refrigeração. Revista Brasileira de Armazenamento, 34:40-48.

Santos JCB, Vilas Boas EVB, Prado MET \& Pinheiro ACM (2005) Avaliação da qualidade do abacaxi "Pérola” minimamente processado armazenado sob atmosfera modificada. Ciência e Agrotecnologia, 29:353-361.

Serek M, Tamari G, Sisler EC \& Borochov A (1995) Inhibition of ethyleneinduced cellular senescence symptoms by 1methylcyclopropene, a new inhibitor of ethylene action. Physiologia Plantarum, 94:229-232.

Silva DFP, Salomão LCC, Siqueira DL, Cecon PR \& Rocha A (2009). Potassium permanganate effects in postharvest conservation of the papaya cultivar Sunrise Golden. Pesquisa Agropecuária Brasileira, 44:669-675.

Silva MG, Oliveira JG, Vitória AP, Corrêa SF, Pereira MG, Campostri-ni E, Santos EO, Cavalli A \& Vargas H (2005) Correlation between ethylene emission and skin colour changes during papaya (Carica papaya L.) fruit ripening. Journal of Physique IV, 125:877-879.

SORBENTSYSTEMS (2010). The problem - Ethylene gas. Disponível em: <http://www.sorbentsystems.com/epaxtech.html>. Acessado em: 10 de novembro de 2010.

Souza MS, Azevedo IG de, Corrêa SF, Silva MG, Pereira MG \& Oliveira JG (2009) Resposta da aplicação do 1-MCP em frutos de mamoeiro ‘Golden’ em diferentes estádios de maturação. Revista Brasileira de Fruticultura, 31:693-700. 